\title{
Moderating Effects of Peer Competence on the Relationship Between Children's Perception of Parenting Attitudes and Depression by Gender
}

\author{
Yu Jin Seo, Sarah Hyoung Sun Kim \\ Department of Counseling Psychology, Korea Baptist Theological University, Daejeon, Korea \\ 성별에 따라 아동이 지각한 부와 모의 양육태도와 우울의 관계에서 \\ 또래 유능성의 조절 효과 \\ 서유진, 김사라형선 \\ 침례신학대학교 상담심리학과
}

\begin{abstract}
Objective: This study aimed to investigate the moderating effects of peer competence between children's perception of parenting attitudes and depression among $5^{\text {th }}$ grade elementary students. The differences are examined based by gender.

Methods: 'The Children's Perception of the Parenting Attitudes Inventory', 'Children's Depression Inventory', and 'Peer Competence Inventory' were used to collect data from 200 elementary school students from Seoul, Korea. The research hypothesis were analyzed using $t$-tests, Pearson's correlation analysis, standard linear regression analysis and hierarchical multiple regression analysis via SPSS 21.0.

Results: The results are as follows: First, only peer competence showed a difference between the boys and girls, where the boys scored higher than the girls. Second, there was a significant correlation between all the factors. Third, the moderating effect of peer competence on the father's parenting attitude was supported only in the boys.

Conclusion: The results denote the need of a gendered approach to understanding problems and developing counseling programs to address depression among children. They also demonstrate that high peer competence can be used to treat depression in boys dissatisfied with their father' parenting attitude.
\end{abstract}

Keywords: children's perception of the parenting attitudes, depression, peer competence, moderating effect

\begin{abstract}
서론
최근 우리나라 초. 중 - 고 생의 정신건강은 심각한 수준이라 할 수 있다. 교육과학기술부는 2012년도에 전체 초 · 중 · 고생

Corresponding Author: Sarah Hyoung Sun Kim, Department of Counseling Psychology, Korea Baptist Theological University, 190, Bugyuseongdaero, Yuseong-gu, Daejeon, Korea.

E-mail: khsahm@hanmail.net
\end{abstract}

들(648만 2천 474명)을 대상으로 정서.행동 특성검사를 실시 하였는데 초.중.고생의 $16.3 \%$ 인 105 만 4 천여 명이 검사 결 과에서 '관심군'으로 나타났다. 이러한 사실은 초. 중·고생의 정신건강 상태가 심각한 수준임을 시사한다. 하지만 현재 우

(C) The Korean Association of Child Studies

This is an Open Access article distributed under the terms of the Creative Commons Attribution Non-Commercial License (http:// creativecommons.org/licenses/by-nc/4.0) which permits unrestricted noncommercial use, distribution, and reproduction in any medium, provided the original work is properly cited. 
리나라에는 정신건강 분야에서 우울에 대한 연구가 주로 청소 년이나 성인을 대상으로 이루어졌고 아동을 대상으로 한 연구 는 활발하게 진행되지 못했다. 이것은 아동의 우울증이 성인 우울증과 증상에 있어 다소 차이가 있고 그 증상이 우울증이 라고 명확하게 명명할 수 없으며 다른 신체적인 반응으로 대 체해서 나타나는 경우도 많기 때문이라고 할 수 있다. 특히, 아 동기 우울은 사춘기를 전후해서 급격히 증가하는데 잠재되어 있는 형태로 나타나기 때문에 일상 상황에서 쉽게 발견하기 어렵다(Lee, 2015). 또한 청소년기의 정서장애와 다양한 사회 기술과 행동장애 저하로 나타나기도 하며, 성인기가 되어 범 죄 - 비행행동, 알코올 중독 등 우울이 지속될 가능성이 높다는 점에서 아동기 우울함에 대한 관심이 요구 된다(Kwon, 2013).

아동기는 인지적, 신체적, 정서적, 사회적으로 급격한 성 장을 하고 있는 시기이므로 이 시기의 우울은 발달 영역 전반 에 거쳐 부정적인 영향을 주게 된다. 아동기 우울증의 증상으 로는 슬픔, 무기력 같은 정서적 우울감과 더불어 짜증, 과다활 동, 공격적 행동, 친구관계 악화, 무단결석, 성적 저하, 신체 증 상과 자살 사고가 나타날 수 있다(K. B. Park \& Shin, 1991). 이 러한 아동기 우울 증상을 방치할 경우 또래 관계에서의 고립 이 야기되고 청소년기에 그 증상이 더욱 심해져 자살 생각이 나 시도에까지 영향을 미칠 수 있다(D. M. Park, 2004). 이에 조 기에 발견하여 대처하는 것이 중요하며 아동기 우울에 영향을 주는 주요 요인에 대한 체계적인 연구도 필요하다.

우울과 관련된 변인으로는 부모의 양육태도가 있다. 자녀 와 부모의 초기 경험은 자녀의 성격형성과 정서 발달에 직접 적인 영향을 미치고 또한 정서적 문제 발생의 가장 본질적인 역할을 한다(Kail, 2003). 특히 우리나라의 아동은 학교, 가정 에서 다양한 측면들을 발달시키고 성숙시키기보다는 부모의 지나친 학업에 대한 기대와 과열된 경쟁 분위기로 인해서 스 트레스를 받고 있다. 그리고 과도한 스트레스로 지친 아동들 은 분노, 과잉행동, 파괴적 행동, 거짓말하기, 도벽, 학습장애, 성격장애, 신경증, 우울증, 열등감 등의 정신증상을 보이게 된 다(M. H. Kang, Chang, \& Jeong, 1998). 부모의 양육태도와 관 련된 선행 연구들을 보면(Baumrind, 1967, 1973; Rapee, 1997; Shaefer, 1965), 부모의 긍정적 양육태도는 자녀에게 자신감을 주어 또래 관계에서 유능성을 보이고 긍정적 정서에 영향을 주지만, 부정적 양육태도는 자녀의 또래 관계에서 유능성이 낮아질 뿐 아니라 우울이라는 부정적 정서에 영향을 미친다.

아동 우울증 환자의 가족환경 변인을 살펴본 연구들에 따 르면, 역기능적인 가족 역동, 거부적, 비판적, 적대적인 환경이 아동의 우울 정도와 지속성에 영향을 준다고 하였다(McGuire
\& Weisz, 1982; Y.-S. Park \& Byun, 2016). 특히 부모의 양육행동 이 아동의 우울을 발전시키고 지속시키는데 중요한 원인으로 작용한다는 이론적 모델들이 계속적으로 나오고 있다(Bowlby, 1973).

아동의 우울과 부모 양육태도에 대한 기존의 선행연구들을 보면 주로 부모보고식 방식으로 이루어져 있어 부모가 보고한 양육태도는 자녀의 입장에서 인식된 양육태도와 다를 수 있 다. 아동은 주변의 상황을 보다 주관적으로 지각하는 특성이 있어 아동에게 인식된 부모 양육태도를 측정하는 것이 더 효 과적일 것이다(Ha, 2006). 이에 본 연구에서는 아동이 지각한 부모 양육태도를 통해 아동의 우울과 또래 유능성을 알아보고 자 하였다.

아동과 부모와의 관계 외에 또래관계도 아동에게 중요한 영향을 미치는 변인이라 할 수 있다. 아동은 초기에 경험한 부 모와의 상호작용을 통하여 또래들과 상호 작용하는 방식을 인식하며, 부모는 아동의 사회적 능력과 또래 수용 정도에 직 접 혹은 간접적으로 영향을 미치기 때문이다(Asher \& Hymel, 1981). 바람직한 또래와의 상호작용은 인지발달이나 사회적 발달에 중요한 영향을 미치게 되며, 대인관계에 대한 기술 습 득이나 탈 중심화, 올바른 성역할의 발달 및 자아개념의 형 성에도 영향을 미치기 때문에 아동이 성장함에 따라 그 중요 성은 더욱 증가하게 된다(S. Y. Kang \& Kang, 2006). 또래관계 와 우울에 대한 선행연구들을 보면, 또래로 부터 지지를 받 는 아동은 그렇지 않은 아동들에 비해 우울 수준이 낮고(Lim, 2005), 또래 유능성이 좋으면 아동이 덜 우울하다고 하였다 (Jang, Noh, \& Lim, 2008; Rhee, 1997). 이에 아동이 부모와의 관계로 인해 우울하다고 할지라도 또래 유능성의 정도에 따라 우울감이 조절 될 수 있다고 가정할 수 있다.

본 연구에서는 성별에 따라 아동이 지각한 부와 모의 양육 태도와 우울과의 관계에서 또래 유능성의 조절효과를 보고자 한다. 성별에 따라 보는 것은 여아가 남아보다 부모의 양육태 도를 더 많이 지각한다는 연구(Rhee, 1997)와 부모의 양육태도 와 성별은 무관하다는 연구(D. M. Park, 2004)의 불일치가 있 어, 성별에 따라 다르게 나올 수 있다는 가정에 의해서이다. 이 외 부와 모를 분리하여 연구를 한 것은, 아버지의 양육태도가 어머니에 비해 영향력이 낮다는 결과(Yoon \& Chung, 2014)와 아버지의 돌봄이 중요하다는 연구(Cho, 2016)에 의거해 부와 모의 영향이 다르게 나올 수 있기 때문이다. 또한 아버지의 자 녀양육 참여나 역할이 강조되고 있는 현 시대의 상황을 고려 해(Cho, 2016), 실증적으로 확인하는 것이 중요하다고 판단해 서이다. 
따라서 본 연구에서는 성별에 따라 아동이 지각한 부와 모 의 양육태도가 아동의 우울함에 어떻게 영향을 미치는지, 또 래 유능성이 부와 모의 양육태도와 우울과의 관계에서 조절효 과를 보일 수 있는지 검증하고자 하였다. 또래 유능성이 부모 양육태도와 우울의 관계에서 조절효과가 나타난다면 아동의 우울을 예방하기 위해 또래 유능성을 향상 시킬 수 있는 프로 그램을 제안 할 수 있을 것이라 기대한다. 이와 같은 연구 목적 을 달성시키기 위해 설정한 연구문제는 다음과 같다.

\section{연구문제 1}

성별에 따라 아동이 지각한 부와 모의 양육태도, 우울, 또래 유능성 간에 차이가 있는가?

\section{연구문제 2}

성별에 따라 아동이 지각한 부와 모의 양육태도, 우울, 또래 유능성간에 어떠한 상관이 있는가?

\section{연구문제 3}

성별에 따라 아동이 지각한 부와 모의 양육태도와 우울 간에 또래 유능성의 조절 효과가 있는가?

3-1 성별에 따라 부의 양육태도와 우울 간에 또래유능성의 조 절효과가 있는가?

3-2 성별에 따라 모의 양육태도와 우울 간에 또래유능성의 조절효과가 있는가?

\section{연구방법}

\section{연구대상}

본 연구는 서울시 소재 2개의 초등학교 5학년 학생 200명을 대상으로 실시하였다. 담임선생님들에게 연구의 목적과 설 문지에 대해 충분히 설명하고 부모의 동의를 얻어 아동들에 게 배부하도록 하였다. 설문지는 총 200 부가 회수되었으며 이 중 불성실하게 응답하거나 응답이 누락된 설문지가 없어서 200 부를 모두 분석에 사용하였다. 5학년 아동을 대상으로 선 정한 이유는 이 시기가 또래 간 상호 작용이 증가하는 시기이 며 또래관계 유능성도 중요한 역할을 하는 시기이기 때문이다 (Bullock, 1989; Ladd, Profilet, \& Hart, 1992).

\section{연구도구}

\section{아동이 지각한 부모 양육태도 척도}

아동이 지각한 부모의 양육태도 척도는 Oh와 Lee (1982)가 개 발하고 M. S. Kim (2013)이 사용한 자녀가 지각한 부모 양육태 도 검사의 4 영역 중 신뢰도가 낮게 나온 문항을 제외하고 총 31 문항을 사용하였다. 본 검사는 5점 리커트식 척도로 구성되 며 점수가 높을수록 양육행동을 긍정적으로 지각하고 있음을 의미한다. 이 검사의 신뢰도(Cronbach's $\alpha$ )는 .91이었다.

\section{아동 우울 척도}

아동의 우울을 측정하기 위해 Kovacs (1983)가 개발하고 S. H. S. Kim (2015)이 사용한 아동용 우울 척도(Children's Depression Inventory [CDI])를 사용하였다. 이 척도는 총 27문 항으로 구성되어 있으며, 각 문항에 대해 3 개의 서술문 중 지 난 2주 동안 자기 자신을 가장 잘 묘사하고 있다고 생각되는 서술문 한 개를 골라 표시하는 자가 우울 평정 척도(Self-Rating Depression Scale)이다. 점수가 높을수록 우울하다고 할 수 있 다. 본 연구에서의 신뢰도 신뢰도(Cronbach's $\alpha$ )는 .84이었다.

\section{또래 유능성 척도}

아동의 또래 유능성을 측정하기 위해서는 J. Park과 Rhee (2001)가 개발한 또래 유능성 척도를 사용하였다. 이 척도는 아동의 또래관계에 관한 기존의 국내의 척도들을 참고하여 제 작한 것으로써 세 개 하위 요인 별로 5 문항씩 총 15 개 문항으 로 구성되어 있다. 이 검사는 5점 리커트식 척도로 구성되어 있으며 점수가 높을수록 또래 유능성이 높다고 할 수 있다. 이 검사의 신뢰도(Cronbach's $\alpha$ )는 .93이었다.

\section{자료분석}

수집된 자료는 SPSS 21.0 (IBM Co., Armonk, NY) 통계 프로그 램을 사용하여 분석하였다. 첫째, 성별에 따라 아동이 지각한 부와 모의 양육태도, 우울, 또래 유능성 간의 성차 검증을 위해 서는 $t$ 검증을 하였다. 둘째, 변인들 간의 상관관계를 검증하기 위해서는 Pearson의 단순상관 분석을 하였다. 셋째, 성별에 따 라 아동이 지각한 부와 모의 양육태도와 우울의 관계에서 또 래유능성의 조절효과를 검증하기 위해서는 SPSS용으로 Hayes 
(2013)가 개발한 PROCESS $2.11 \mathrm{Macro}$ 를 사용하여 단계적 중 다회귀분석을 하였다.

\section{연구결과}

\section{성별에 따라 아동이 지각한 부와 모의 양육태도, 우울, 또래 유능성 수준의 차이}

성별에 따라 아동이 지각한 부와 모의 양육태도, 우울, 또래 유 능성간에 차이가 있는지를 알아보기 위하여 평균과 표준편차를 산출 한 후 $t$ 검증을 실시하였고 그 결과는 Table 1 에 제시하였다.

Table 1에서와 같이 우울에서는 남아와 여아 간에 유의한 차이가 없었고 부의 양육태도와 모의 양육태도도 남아와 여아 간에 유의한 차이가 없었다. 또래 유능성에서만 남아와 여아 간에 유의한 차이가 나타났으며 여아가 남아보다 또래 유능성 의 점수가 높게 나타났다 $(t=.27, p<.05)$.

\section{성별에 따라 부와 모의 양육태도, 우울, 또래 유능성의 상관관계}

성별에 따라 부와 모의 양육태도, 우울, 또래 유능성의 상관관 계를 살펴보기 위해 피어슨의 상관계수를 산출하였고 그 결과 는 Table 2에 제시하였다.

Table 2에 제시된 것처럼, 분석결과 먼저 남아의 경우, 부 의 양육태도와 우울에서 부적 상관을 보였고 $(r=-.62, p<.01)$, 모의 양육태도와 우울에서도 부적 상관을 보였다 $(r=-.43, p<$ .01). 부의 양육태도와 또래 유능성에서는 정적 상관을 보였고 $(r=.49, p<.01)$, 모의 양육태도와 또래 유능성에서도 정적 상 관을 보였다 $(r=.58, p<.01)$. 부의 양육태도와 모의 양육태도 는 정적상관을 보였고 $(r=.74, p<.01)$, 또래유능성과 우울에 서는 부적상관을 보였다 $(r=-.53, p<.01)$.

여아의 경우도 남아와 마찬가지로 부의 양육태도와 우울에 서 부적 상관을 보였으며 $(r=-.39, p<.01)$ 모의 양육태도와 우 울에서도 부적 상관을 보였다 $(r=-.42, p<.01)$. 부의 양육태도

Table 1

Differences Among Depression, Parenting Attitude, and Peer Competence by Gender

\begin{tabular}{|c|c|c|c|c|}
\hline \multirow[b]{2}{*}{ Division } & \multirow[b]{2}{*}{ Major factor } & \multicolumn{2}{|c|}{$M(S D)$} & \multirow[b]{2}{*}{$t$} \\
\hline & & Boys & Girls & \\
\hline \multirow[t]{2}{*}{ Parenting attitude } & Father & $3.88(.76)$ & $4.02(.52)$ & -1.46 \\
\hline & Mother & $4.00(.59)$ & $4.08(.51)$ & 1.03 \\
\hline Peer competence & & $3.78(.82)$ & $4.03(.67)$ & $2.27^{*}$ \\
\hline Depression & & $1.38(.25)$ & $1.37(.23)$ & .26 \\
\hline
\end{tabular}

Note. boys $(N=101)$; girls $(N=99)$.

${ }^{*} p<.05$.

Table 2

Correlations of Depression, Father's Parenting Attitude, and Peer Competence by Gender

\begin{tabular}{llcc}
\hline \multicolumn{1}{c}{ Variables } & 1 & 2 & 3 \\
\hline Boy & 1. Peer competence & - & - \\
& 2. Father's parenting attitude & $.49^{* *}$ & $.74^{* *}$ \\
3. Mother's parenting attitude & $.58^{* *}$ & $-.62^{* *}$ \\
\hline 4. Depression & $-.53^{* *}$ & - & $-.43^{* *}$ \\
\hline 1. Peer competence & - & $.57^{* *}$ & $.84^{* *}$ \\
2. Father's parenting attitude & $.59^{* *}$ & $-.39^{* *}$ & $-.42^{* *}$ \\
3. Mother's parenting attitude & $-.44^{* *}$ &
\end{tabular}

Note. boys $(N=101)$; girls $(N=99)$.

${ }^{* *} p<.01$. 
와 또래 유능성에서는 정적 상관을 보였고 $(r=.57, p<.01)$, 모 의 양육태도와 또래 유능성에서도 정적 상관을 보였다 $(r=.59$, $p<.01)$. 부의 양육태도와 모의 양육태도는 정적상관을 보였 고 $(r=.84, p<.01)$, 또래 유능성과 우울의 관계에서는 부적상 관을 보였다 $(r=.44, p<.01)$.

\section{성별에 따라 아동이 지각한 부와 모의 양육태도, 우울의 관계에서 또래 유능성의 조절 효과}

성별에 따라 아동이 지각한 부의 양육태도와 우 울 간에 또래 유능성의 조절효과

성별에 따라 아동이 지각한 부의 양육태도와 우울 간에 또래 유능성의 조절효과를 검증하기 위해서 독립변인인 부의 양육 태도와 조절변인인 또래 유능성을 원 점수에서 평균값을 뺀 평균중심화(centering)로 변환하여 두 변인을 곱한 상호작용 변인을 만든 후 단계적 중다회귀분석을 실시하였다. 남자 아
동의 우울과 부의 양육태도 간에 또래 유능성의 조절효과를 분석한 결과는 Table 3 에 제시하였다. Table 3 에 제시된 바와 같 이 조절효과의 설명량은 $2 \%(F=4.45, p<.01)$ 로 유의한 것으 로 나타났다.

조절효과를 시각적으로 살펴보기 위해 그래프로 Figure 1 에 제시하였다. Figure 1에서 보면, 또래 유능성이 높은 아동은 낮은 경우에 비해 아버지의 부정적 양육태도 수준이 높아지는 것에 따른 우울 상승 폭이 작았다. 이는 남자 아동에게서 부의 부정적 양육태도로 인해 우울을 유발하는 관계를 또래 유능성 이 조절해 줌을 의미한다.

여자 아동의 우울과 부의 양육태도 간에 또래 유능성의 조절효과를 분석한 결과는 Table 4에 제시하였다. Table 4에 제시된 바와 같이 조절효과의 설명량은 유의하지 않은 것으 로 나타났다. 구체적으로 살펴보면 아버지의 양육태도의 주 효과는 유의하지 않았고, 또래 유능성의 주효과는 유의했으 며 $(t=-2.79, p<.05)$, 조절효과는 통계적으로 유의하지 않 았다.

Table 3

Moderating Effects of Peer Competence Between Father's Parenting Attitude and Depression Among Boys

\begin{tabular}{lcccc}
\hline \multicolumn{1}{c}{ Independent variable } & $B$ & $S E$ & $t$ & $R^{2}$-change \\
\hline Consonant & 37.88 & .58 & $64.76^{* * *}$ & .02 \\
Father's parenting $(\mathrm{X})$ & -.13 & .02 & $-5.14^{* * *}$ & $4.45^{* * *}$ \\
Peer competence $(\mathrm{Z})$ & -.22 & .05 & $-4.41^{* * *}$ \\
Father's parenting $\times$ peer competence $(\mathrm{XZ})$ & -.00 & .00 & $-2.11^{*}$ & \\
\hline
\end{tabular}

Note. $N=101$.

${ }^{*} p<.05 .{ }^{* * *} p<.001$.

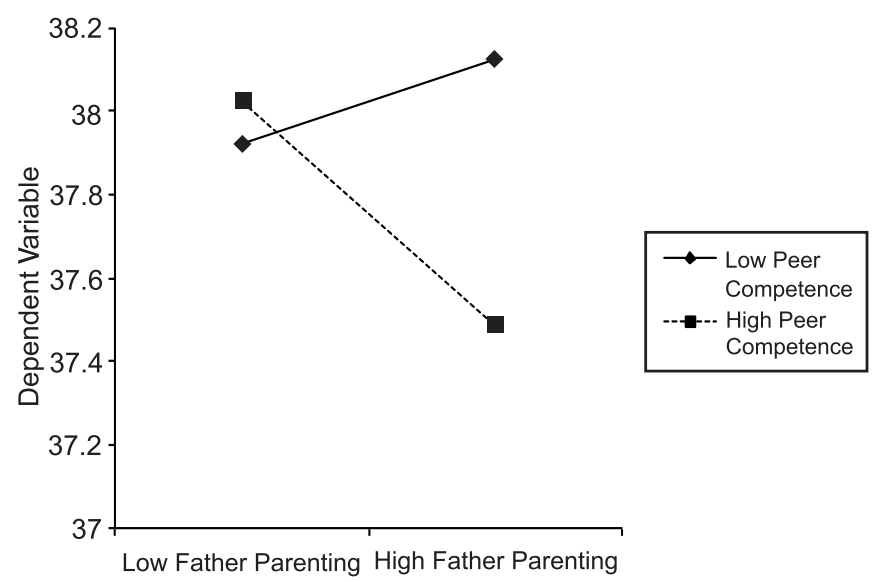

Figure 1. Moderating effects of peer competence between father's parenting attitude and depression among boys. 
Table 4

Moderating Effects of Peer Competence Between Father's Parenting Attitude and Depression Among Girls

\begin{tabular}{lcccc}
\hline \multicolumn{1}{c}{ Independent variable } & $B$ & $S E$ & $t$ & $R^{2}$-change \\
\hline Consonant & 36.92 & .63 & $57.77^{* * *}$ & .00 \\
Father's parenting $(\mathrm{X})$ & -.13 & .02 & -1.66 & .02 \\
Peer competence $(\mathrm{Z})$ & -.12 & .05 & $-2.79^{*}$ & \\
Father's parenting $\times$ peer competence $(\mathrm{XZ})$ & -.00 & .00 & -.15 & \\
\hline
\end{tabular}

Note. $N=101$.

${ }^{*} p<.05 .{ }^{* * *} p<.001$.

Table 5

Moderating Effects of Peer Competence Between Mother's Parenting Attitude and Depression Among Boys

\begin{tabular}{|c|c|c|c|c|c|}
\hline Independent variable & $B$ & $S E$ & $t$ & $R^{2}$-change & $F$ \\
\hline Consonant & 37.38 & .64 & $58.79^{* * *}$ & .00 & .00 \\
\hline Mother's parenting $(\mathrm{X})$ & -.07 & .03 & $-2.10^{* * *}$ & & \\
\hline Mother's parenting $\times$ peer competence $(\mathrm{XZ})$ & -.00 & .00 & -.02 & & \\
\hline
\end{tabular}

Note. $N=99$.

${ }^{*} p<.05 .{ }^{* * *} p<.001$.

Table 6

Moderating Effects of Peer Competence Between Mother's Parenting Attitude and Depression Among Girls

\begin{tabular}{lcccc}
\hline \multicolumn{1}{c}{ Independent variable } & $B$ & $S E$ & $t$ & $R^{2}$-change \\
\hline Consonant & 37.13 & .60 & $61.01^{* * *}$ & .00 \\
Mother's parenting $(\mathrm{X})$ & -.13 & .04 & $-3.28^{* *}$ & .11 \\
Peer competence $(\mathrm{Z})$ & -.16 & .07 & -2.27 & \\
Mother's parenting $\times$ peer competence $(\mathrm{XZ})$ & -.00 & .00 & -.03 & \\
\hline
\end{tabular}

Note. $N=99$.

${ }^{* *} p<.01 .{ }^{* * *} p<.001$.

성별에 따라 아동이 지각한 모의 양육태도와 우 울 간에 또래 유능성의 조절효과

성별에 따라 아동이 지각한 모의 양육태도와 우울 간에 또래 유능성의 조절효과를 검증하기 위해서 독립변인인 모의 양육 태도와 조절변인인 또래 유능성을 원 점수에서 평균값을 뺀 평균중심화(centering)로 변환하여 두 변인을 곱한 상호작용 변인을 만든 후 단계적 중다회귀분석을 실시하였다. 남자 아 동의 결과는 Table 5 에 여자 아동의 결과는 Table 6에 제시하였 다.

Table 5에 제시된 바와 같이 조절효과의 설명량은 유의하지 않은 것으로 나타났다. 구체적으로 살펴보면 어머니 양육태도 의 주 효과는 유의하였고 $(t=-2.10, p<.001)$, 또래 유능성의 주
효과도 유의했으나 $(t=-4.39, p<.05)$, 조절효과는 통계적으로 유의하지 않았다.

Table 6에 제시된 바와 같이 조절모형의 설명량은 유의하지 않은 것으로 나타났다. 구체적으로 살펴보면 어머니 양육태도 의 주 효과는 유의하였고 $(t=-3.28, p<.01)$, 또래 유능성의 주 효과는 유의하지 않았으며, 조절효과도 통계적으로 유의하지 않았다.

\section{논의 및 결론}

본 연구에서는 아동이 지각한 부와 모의 양육태도, 우울, 또래 유능성 간의 관계를 성별에 따라 검증하고자 하였다. 구체적 
으로는 첫째, 성별에 따라 아동이 지각한 부와 모의 양육태도, 우울, 또래 유능성 간에 차이가 있는지, 둘째, 아동이 지각한 부와 모의 양육태도, 우울, 또래 유능성 간에 상관관계를 보고 자 하였다. 마지막으로, 아동이 지각한 부와 모의 양육태도와 우울의 관계에서 또래유능성의 조절효과가 있는지 검증하고 자 하였다.

본 연구에서 밝혀진 결과를 중심으로 논의를 전개하면 다 음과 같다. 첫째, 성별에 따라 아동이 지각한 부와 모의 양육태 도, 우울, 또래 유능성의 차이를 검증한 결과 오직 또래 유능성 에서만 성별의 차이가 있었으며 여학생이 남학생보다 더 높은 또래 유능성 수준을 보였다. 이 결과는 여아가 남아보다 부모 의 양육태도를 더 많이 지각한다는 결과(Rhee, 1997)와 상반된 다. 하지만 부모의 성별은 무관하다(D. M. Park, 2004)는 결과 와는 일치한다.

둘째, 성별에 따라 부와 모의 양육태도, 우울, 또래 유능성 의 상관관계에 대한 결과를 살펴보면, 남학생과 여학생 모두 부와 모의 양육태도와 우울에서 부적 상관을 보였다. 이 결과 는 어머니의 양육태도에 따라 자녀의 사회적 활동과 정서에 부정적 영향을 미친다는 연구(Choi \& Lee, 2011)와 부의 양육 태도가 사회불안과 우울에 영향을 미친다는 연구(M. K. Kim, $\mathrm{Oh}, \& \mathrm{Oh}, 2005)$ 와 일치한다. 이외에도 부모의 양육태도가 우 울에 직접 영향을 미치기 보다는 긍정적 스트레스 대처행동 과 자기통제를 매개하여 영향을 미친다는 결과(Choi \& Lee, 2011)를 다소 지지한다. 부모의 양육행동자체가 아동의 우울 에 영향을 주기보다는 비합리적, 비성취적인 부정적 양육행 동이 아동의 비 효율적인 스트레스 대처방식을 유발하게 되 고 이것으로 인해 우울, 불안, 적대감과 같은 부정적인 정서를 느끼게 된다는 것이다. 이는 부모의 양육행동이 부정적일수록 아동은 스트레스 상황에서 위축되고 주위로부터 부정적 평가 를 받게 되며 그로 인해 자기 비하 및 부정적 생각을 갖게 되어 우울하게 된다고 판단할 수 있다. 이와 같이 아버지, 어머니의 양육태도는 모두 직·간접적으로 자녀의 우울에 영향을 미친 다고 해석할 수 있다.

부모의 양육태도와 또래 유능성에 있어서도 남학생 여학 생 모두에서 상관이 있음이 나타났다. 이 결과는 남학생과 여 학생을 구분하지는 않았지만 부모의 양육태도와 또래 유능성 에 상관이 있다는 Jung (2001)의 결과와 다소 일치한다. 이외 또래 유능성과 우울의 관계를 보면 남학생과 여학생 모두에서 상관을 보였다. 이는 또래 유능성과 우울 간에 상관이 있다는 D. M. Park (2004)의 연구와 상통한다. 즉 부모의 긍정적 양육 태도는 자녀에게 자신감을 주어 또래 관계에서 유능성을 나타
낼 수 있어 삶속에서 긍정적 정서를 경험하지만 부정적 양육 태도로 양육된 자녀들은 또래관계에서 유능성이 낮아질 뿐 아 니라 우울이라는 부정적 정서도 경험할 수 있어서라고 판단할 수 있다. 남. 여 간의 점수 차이를 보면, 부와 모의 양육태도, 우울, 또래 유능성 모두에서 남학생이 여학생 보다 점수가 높 게 나타났다.

셋째, 성별에 따라 부의 양육태도와 우울 간에 또래 유능성 의 조절효과를 살펴보면, 남자 집단에서만 부의 양육 태도가 우울에 미치는 영향 간에 또래 유능성의 조절효과가 나타났 다. 이러한 결과는 부의 양육태도로 인해 남자 아동이 우울하 다고 할지라도 또래 유능성 수준이 높으면 우울에 미치는 영향 을 조절할 수 있다고 해석된다. 이 결과는 아버지의 양육태도 가 어머니에 비해 영향력이 낮다는 결과(Yoon \& Chung, 2014) 와는 다소 다르지만, 모의 돌봄이 중요하며 부의 긍정적인 돌 봄이 자녀의 자아탄력성을 증진시켜 대인관계를 잘한다는 결 과(Cho, 2016)와는 유사하다. 부의 양육태도가 남아에게서 조 절효과가 나타난 것은 남아의 특성상 모보다는 부의 영향력이 더 커서이기 때문(Cho, 2016)이라고 해석할 수 있다. 따라서 부 의 양육태도로 인하여 우울하다고 할지라도 또래와의 관계에 서 유능성이 높으면 우울에 덜 영향을 받는다고 할 수 있다. 이 에 부로부터 오는 남아의 우울을 감소시키기 위해서는 아동의 또래 유능성 수준을 높이는 것이 필요하다고 할 수 있다.

본 연구의 의의는 초등학생의 또래 유능성이 성별에 따라 차이가 있음을 규명한 점이다. 그리고 남학생이 지각한 부의 양육태도와 우울 간의 관계에서 또래 유능성의 조절효과를 밝 혔다는 점이다. 성별에 따라 또래 유능성의 조절효과를 밝혔 다는 점은 성별에 따라 차별화된 프로그램 개발 및 처치가 필 요함을 시사한다. 특히 남학생의 경우 부의 양육태도가 건강 하지 않은 상황에서 우울을 예방하고 이에 대해 개입 및 치료 하기 위해서는 또래 유능성을 증진시키는 것이 중요하며 이를 위한 상담 및 심리치료 중재 프로그램에 대한 시사점을 마련 해 주었다는 점에서 의의를 찾을 수 있다.

끝으로 본 연구의 제한점을 토대로 후속연구를 위한 제언 은 다음과 같다. 첫째, 본 연구는 서울지역에 소재하는 두 개의 초등학교 5학년 학생들만을 대상으로 했기 때문에 연구결과 를 일반화시키기에 제한이 있을 수 있다. 따라서 추후 연구에 서는 광범위한 연령과 지역을 대상으로 한 연구가 이루어지기 를 제언한다. 둘째, 본 연구는 성별에 따라 아동의 지각한 부와 모의 양육태도와 우울, 또래 유능성에 대한 선행연구의 부족 으로 결과를 논의하는데 제한이 있었다. 또래 이에 성별에 따 라 연구가 지속되기를 제언한다. 셋째, 본 연구는 초등학교 5 
학년 학생의 주관적인 보고에 의존한 자기보고식 척도를 사용 하였기 때문에 설문 응답자가 실제보다 더 큰 정서 상태를 보 고할 가능성과 사회적 바람직성에 따라 보고할 가능성을 배제 할 수 없다. 그리고 부모의 보고와 같은 다른 추가적 방식을 통 해 얻을 수 있는 중요한 정보가 간과되었을 가능성이 있다. 따 라서 후속 연구에서는 자기 보고식 연구가 지닐 수 있는 문제 점을 보완함으로써 결과의 타당성을 높이고, 아동의 보고 뿐 아니라 부모의 보고까지 포함하여 그 차이를 비교하는 심층적 연구가 이루어질 필요가 있다. 마지막으로, 본 연구에서 다루 고자 했던 또래 유능성의 개념과 정확히 부합하는 선행 연구 의 부재로 인해 논의에 많은 제약이 있었다. 본 연구에서 사용 한 또래 유능성 척도는 J. Park과 Rhee (2001)가 개발한 또래 유 능성 척도를 사용하였다. 이 척도는 사교성, 친사회성, 주도성 으로서 구성되었는데 이러한 문항들로는 또래 유능성을 측정 하는데 한계가 있다. 또래 유능성을 정확히 측정하기 위해서 는 부모가 아동을 관찰하는 것과 교사가 아동을 관찰하여 하 는 평가가 같이 이루어져야 한다. 하지만 이러한 평가도 부모 나 교사의 개인적인 판단이 들어갈 수 있으며 관찰하는 것에 대한 시간적 제약이 따를 수 있기 때문에 이러한 점을 보완한 다차원적인 새로운 측정도구가 개발되기를 제언한다.

\section{Notes}

This article is a part of the first author's master's thesis and was presented at the 2016 Annual Fall conference of the Korean Association of Child Studies.

\section{Conflict of Interest}

No potential conflict of interest relevant to this article was reported.

\section{References}

\section{In English}

Asher, S. R., \& Hymel, S. (1981). Children's social competence in peer relations: Sociometric and behavioral assessment. In J. Wine \& H. Syme (Eds.), Social competence (pp. 125-157). New York: Guilford Press.

Baumrind, D. (1967). Effects of authoritative parental on child behavior. Child Development, 37(4), 887-907. doi: $10.2307 / 1126611$

Baumrind, D. (1973). The development lf instrumental competence through socialization. In A. D. Pick (Ed.), Minnesota symposia on child psychology (pp. 3-46). Minneapolis: University of Minnesota Press.

Bowlby, J. (1973). Attachment and loss: Vol 2. Separation, anxiety, and anger. New York: Basic Books.

Bullock, J. R. (1989). The relationship between parental management of peer interactions and children's social competence. Family \& Consumer Sciences Research Journal, 17(3), 263-269. doi:10.1177/1077727X8901700306

Hayes, A. F. (2013). Introduction to mediation, moderation, and conditional process analysis: A regression-based approach. New York: The Guilford Press.

Kail, R. V. (2003). Children and their development. NJ: PrenticeHall.

Kovacs, M. (1983). The Children's Depression Inventory: A self-rating depression scales for school-aged youngsters (Unpublished manuscript). Pittsburgh, PA: University of Pittsburgh.

Ladd, G. W., Profilet, S. M., \& Hart, C. H. (1992). Parents' management of children's peer relations: Facilitating and supervising children's activities in the peer culture. In R. D. Parke \& G. W. Ladd (Eds.), Family-peer relationships: Modes of linkage (pp. 215-253). Hillsdale, NJ: Lawrence Erlbaum Associates.

McGuire, K. D., \& Weisz, J. R. (1982). Social cognition and behavior correlates of preadolescent chumship. Child Development, 53(6), 1478-1484. doi:10.2307/1130074

Rapee, R. M. (1997). The potential role of child rearing practices in the development of anxiety and depression. Clinical Psychology Review, 17(1), 47-67. doi:10.1016/S02727358(96)00040-2

Schaefer, E. S. (1965). Children's reports of parental behavior: An inventory. Child Development, 36(2), 413-424. doi:10.2307/1126465

\section{In Korean}

Cho, G. S. (2016). A study on the effects of perceived parenting attitudes on regulatory focus among college students: Mediating the effects of ego-resiliency. Korean Journal of Child Studies, 37(5), 19-31. doi:10.5723/kjcs.2016.37.5.19

Choi, Y.-K., \& Lee, J.-Y. (2011). The relation between parenting and children's depression: Testing the mediating effects of positive stress-coping behavior and self-control. The Journal of Child Education, 20(2), 235-251.

Ha, M.-S. (2006). Children-perceived parents' rearing attitude and self elasticity and their influence on school life (Master's thesis). Retrieved from http://www.riss.kr/link?id=T10809297 
Jang, A. N., Noh, A. Y., \& Lim, S. J. (2008). The relations among early object relationship perceived by adolescents, peer relationship and depression. The Korea Journal of Counseling, 9(2), 727-737.

Jung, S. Y. (2001). Relationship between parenting behavior and child's conflict resolution strategy (Master's thesis). Retrieved from http://www.riss.kr/link?id=T7914941

Kang, M. H., Chang, Y. J., \& Jeong, J. O. (1998). Child mental health. Seoul: Jeong Min-Sa.

Kang, S. Y., \& Kang, M. H. (2006). Relationships among mother's perfectionism, child-rearing attitude and children's interpersonal relations disposition. Journal of Student Guidance and Counseling, 19, 53-73.

Kim, M. K., Oh, Y. H., \& Oh, K. S. (2005). The effects of perceived parenting behavior on social anxiety symptoms. Korean Journal of Clinical Psychology, 24(3), 599-614.

Kim M. S. (2013). The relationship between the perceived parenting attitude and friendship quality: The mediating effects of selfregulation ability (Master's thesis). Retrieved from http:// www.riss.kr/link?id=T13242578

Kim, S. H. S. (2015). Effects of an integrative group counseling program on decreasing depression, increasing interpersonal relationship and internal locus of control of children. Asian Journal of Child Welfare and Development, 13(4), 21-39.

Kwon, S. M. (2013). Modern psychology. Seoul: Hakjisa.

Lee, Y. K. (2015). The influences of children's anger on depression and aggression: Moderating effects of anger coping style and selfesteem (Doctoral dissertation). Retrieved from http://www. riss.kr/link?id=T13640867

Lim, E.-C. (2005). The relationships between anxiety/depression and friendship characteristics in elementary school children (Master's thesis). Retrieved from http://www.riss.kr/ link?id=T9715351

Oh, S. S., \& Lee, J. S. (1982). The relationship of child's perception to parenting style and affective characteristics (RN 82-1101). Seoul: Korea Institute for Research in the Behavioral Science.
Park, D. M. (2004). The Relationship between parenting styles and children's peer competence (Master's thesis). Retrieved from http://www.riss.kr/link?id=T9730085

Park, J., \& Rhee, U. (2001). Development of a peer competence scale for preschool children. Journal of the Korean Home Economics Association, 39(1), 221-232.

Park, K. B., \& Shin, M. S. (1991). Perceived stress and suicidal ideation in high school students. Korean Journal of Clinical Psychology, 10(1), 298-314.

Park, Y.-S., \& Byun, S-H. (2016). Mediating effect of self-efficacy in the relationship between parenting attitude and rational career decision-making type of middle school students. Journal of the Korea Academia-Industrial Cooperation Society, 17(3), 317-331. doi:10.5762/KAIS.2016.17.3.317

Rhee, U. (1997). Maternal support networks, perceptions of parenting difficulty, and children's development. Journal of Korea Home Economics Association, 35(3), 31-45.

Yoon, S. Y., \& Chung, K.-M. (2014). The relationship between the level of perceived parental over protectiveness and college students' morality. Korean Journal of Culture and Social Issues, 20(4), 307-328.

\section{ORCID}

Yu Jin Seo

http://orcid.org/0000-0002-5293-1064

Sarah Hyoung Sun Kim http://orcid.org/0000-0001-5658-8403

Received April 30, 2017

Revision received May 31, 2017

Accepted June 16, 2017 